\title{
Posing the Question: Visitor Posing as Embodied Interpretation in an Art Museum
}

\author{
Rolf Steier \\ University of Oslo
}

\begin{abstract}
This article identifies and explores posing by visitors to an art gallery as a unique meaning making activity. Conducted as a design experiment in partnership with a national art museum, this study builds on theoretical perspectives related to gesture and embodiment. Empirical findings suggest that particular posing activities function simultaneously to mediate internally and externally oriented processes of interpretation in encounters with art. Accordingly, these complex posing practices may be viewed as an integrated part of visitors' meaning making experiences. Implications for this research include expanding our understanding of the roles of the body in visitor's museum experiences.
\end{abstract}

\section{INTRODUCTION}

Posing with art is a largely unexplored yet significant aspect of the cultural practice of participation at museums. Around the world, we commonly see visitors and tourists posing in front of statues, paintings, or other monuments or works of art. On a near daily basis, when passing through the famous Vigeland Sculpture Park in Oslo, I see visitors posing for a friend with a camera, mimicking and gesturing with the statues. Just as a museum visitor turns her camera toward a friend's pose in front of a famous piece of art, we too must shift focus to the phenomenon of posing with art. These behaviors are not new themselves, but trends in social media have made them particularly visible — both as a way of documenting and sharing these interactions and as a form of participation with these places. But what is happening when visitors pose? How can we understand these behaviors as interactions with art and as social phenomena?

Jaworski and Thurlow (2009) specifically explore such tourist performances as behaviors that, in coordination with a variety of semiotic resources, fundamentally shape a sense of place and identity for tourists. Such performances, although not strictly the subject of this article, are a

Correspondence should be sent to Rolf Steier, University of Oslo, Department of Education, P.O. Box 1161, Blindern, Oslo 0318, Norway. E-mail: rolf.steier@intermedia.uio.no 
useful starting point for demonstrating the pervasiveness of these acts of posing with art and other cultural artifacts.

Only quite recently have art museums begun to build these patterns of use into visitor experiences. The exhibit presented in this study invited visitors to engage with the self-portrait genre by posing and comparing their own compositions. The Cleveland Museum of Art has recently introduced an interactive exhibition in which visitors are invited to make facial expressions and poses, which are in turn connected to similar works in the gallery through body and facial recognition software (Alexander, Barton, \& Goeser, 2013). Although the practice dates back over a century, tableaux vivantes (living pictures) have more recently been embraced as an elementary school activity in which groups of students dress up and pose to depict historical scenes from paintings (Hurwitz \& Day, 2007). Anatomy exhibitions of preserved human bodies have toured science centers around the world in the past decade, and have drawn attention to visitors' physicalities. Vom Lehn (2006) examined visitors relating their own bodies to those in one such exhibit. He demonstrated that "the bodily actions of the participants are critical for how they each view the exhibits" (p. 235). By pointing and orienting their bodies to the objects on display, visitors made comparisons with those in the exhibit. Vom Lehn writes that visitors "discover certain aspects of an exhibit, transpose them onto their body and then talk about it in the light of the discovery of the exhibit feature" (2006, p. 243).

In this article, I attempt to extend current understandings of visitor meaning making processes in art museums by incorporating aspects of the physical experience. Specifically, I identify certain posing activities as embodied action related to particular forms of gesture. These poses mediate the intertwined processes of social interaction on the intermental plane and psychological processes on the intramental plane (Vygotsky, 1978; Wertsch, 1985, 1998). I argue that these processes may be understood as central to meaning making.

\section{Making Meaning in Art Museums}

Historically, research on interpretation in art history (as opposed to meaning making in art museum settings) has been grounded in perception-oriented perspectives focused on an individual viewer (Pierroux, 2006). Information-processing research is similarly concerned with modeling cognitive aspects of visitors' perceptual processes in art interpretation, often studied in controlled settings (Leder, Belke, Oeberst, \& Augustin, 2004). However, such a focus on individual mental processes does not account for the social, institutional, and mediational role of other actors, contexts, and resources.

In contrast with models of individual interpretive processes, this study is grounded in a sociocultural perspective on meaning making. An individual's meaning making processes are situated in overlapping personal, physical, and sociocultural contexts (Falk \& Dierking, 2000). In art museums, these processes may be understood as forms of participation by visitors with tools, symbols, activities, and people (Piscitelli \& Weier, 2002; Schauble, Leinhardt, \& Martin, 1997). Knowledge, thus, involves the ability to participate in these contexts (Leinhardt \& Knutson, 2004). According to sociocultural theory, meaning potentials are embedded in cultural tools such as language and concepts that mediate human thinking and activity (Vygotsky, 1978; Wertsch, 1985). Pieces of art thus cultural objects embedded with meaning potentials developed in particular social and historical contexts (Bakhtin, 1986; Pierroux, 2003). Language and gesture are 
among the cultural tools that mediate visitors' situated interactions with art and with one another, as are art historical concepts and information provided in texts, labels, and technologies in the gallery spaces. For young people, meaning making in art museums involves processes of understanding the skills and techniques of the artist and relating their own ideas, feelings, and personal histories with those of the artist (Pierroux, 2005; Piscitelli \& Weier, 2002).

Studies of museum meaning making that are grounded in a sociocultural perspective often focus primarily or exclusively on visitor talk with the visitor's body backgrounded (Allen, 2002; Hohenstein, 2006; Knutson \& Crowley, 2010; Leinhardt, Crowley, \& Knutson, 2002; Pierroux, 2003; Stainton, 2002). These studies demonstrate the significance that words and language play in visitor meaning making. Alternatively, studies of gesture and body in museums often focus on social coordination and not meaning making processes. In particular, discussions of gesture typically focus on its communicative role in social interaction in museums. For example, visitors may use pointing gestures to direct each other's attention in an exhibit (Ash, 2004; vom Lehn, Heath, \& Hindmarsh, 2001). These studies often treat gesture primarily as a communicative tool, that is, as externally oriented symbolic action.

However, meaning making can be thought of as occurring on both internal and external planes (Vygotsky, 1978; Wertsch, 1985). Externalization processes are socially visible displays of symbolic meaning. Internalization processes explain how these external representations develop in cognition. These psychological processes of internalization and externalization are dialectically related (Vygotsky, 1978; Wertsch, 1985, 1998). The limited research that has addressed the visitor's body in museums has not accounted for the complexities of the simultaneous and overlapping internal and external orientations of the body in situated action. As is expanded below, this article refers to a pose or gesture as externally oriented when its primary role is communicative and intended to display meaning for another person. Internally oriented posing is directed toward the self and coordinates conceptual work of the individual (Streeck, 2009b). This study expands on this research by exploring the mutually constituted relationship between internally and externally oriented aspects of posing (as one type of physical experience) and their relationship to processes of meaning making in encounters with art.

The setting for this research is a museum installation that was part of a larger design experiment conducted through a partnership with a national museum of art. This project consisted of the design, installation, and research of an interactive space that aimed to engage young people in the work of Edvard Munch and art concepts in general. Video recordings of teenage visitors' interactions in the gallery space, and with one of four interactive stations in the project room, compose the main empirical material. The station is titled My Self and was designed to engage visitors in learning about Munch's self-portraits and the self-portrait genre. Visitors were encouraged to recreate the self-portraits by posing and taking pictures. Using multiple sources of video data collected at the gallery, interaction analysis methods (Derry et al., 2010; Hall, 2000; Jordan \& Henderson, 1995) were applied to the investigation of visitor experiences in both the existing gallery space and the designed project room. Through this study, the following research questions were addressed: What is occurring when visitors pose with artwork in a museum? More specifically, what is the nature of the relationship between internally and externally oriented aspects of posing? And how might acts of posing relate to visitor meaning making processes in art museums? 


\title{
PERSPECTIVES ON EMBODIMENT, GESTURE, AND POSING
}

\begin{abstract}
Although there are many forms of posing, I am particularly interested in the art museum context, and I treat posing as a socially situated interaction with an artwork. Posing occurs when a visitor attempts to mimic or re-create a figure from a piece of art with their body. In the following section, I conceptualize posing in relation to ideas of embodiment and gesture. Within the arena of gesture, I identify key forms of gestural practice to interpret these activities. I then establish posing with art as a unique meaning making activity worthy of investigation.
\end{abstract}

\section{Posing as Embodied Action}

The concept of embodiment has gained currency in recent years, particularly in light of new forms of interaction and engagement with technology. This perspective offers a promising starting point for conceptualizing activities of posing, in particular the relationship between the physical actions of the body and meaning making processes (e.g., Cheville, 2006; Dourish, 2004; Farr, Price, \& Jewitt, 2012). Merleau-Ponty's (1945/1974) notion that the body is central to all interactions and knowing in the world aligns with this article's exploration of the body in museum experiences. In treating acts of perception as physiological as well as psychological (1945/1974; Joy \& Sherry, 2003), Merleau-Ponty also establishes a starting point for approaching acts of posing in relation to visitors' aesthetic experiences. This emphasis on the physical was also the basis of Lakoff and Johnson's (1999) examination of the concept of metaphor, which showed how people relate physical experiences into abstract concepts and ideas. These metaphors develop into abstract concepts as children develop and allow people to communicate with and think about abstract concepts (Farr et al., 2012). However, the embodiment concept may be too broad on its own to be helpful in analyzing the meaning making aspects of the activity of visitors posing in an art gallery. Goodwin (2000) writes that, "rather than locating a homogeneous field for analysis, the notion of embodiment encompasses many different kinds of phenomena" (p. 1519). These may include orientation, gesture, and intonation, among other physical aspects of interaction. Accordingly, we can interpret posing with art as one such phenomenon within a framework of embodied interaction-situated within and interrelated to a variety of aspects of embodiment. However, to understand the complex processes of posing in a museum, an analytic framework is needed. Thus we turn to gesture, as a form of embodied action.

\section{Posing as Gesture}

Gesture is a semiotic system for socially coordinated action and thought, much like verbal language (Goodwin, 1986; Kendon, 1983). Through conversation analysis, Goodwin (1986) illustrates the ways in which gesture functions as a complimentary semiotic system to talk. He writes, "In brief, gesture is not simply a way to display meaning but an activity with distinctive temporal, spatial, and social properties that participants not only recognize but actively use in the organization of their interaction" (Goodwin, 1986, p. 47). Gestures are not simply stand-alone representations of meaning but function as a reflexive and dynamic display that exists as a fundamental component of human interaction (Goodwin, 2000). Meaning is not presented by gesture but develops, in part, through gestural interaction. 
One influential framework is that of McNeill (1992), which identified four categories of gesture-beat, deictic, iconic, and metaphoric. Beat gestures do not display content but instead are used to provide emphasis or denote time in structuring communication. Deictic gestures involve pointing and are thus heavily context dependent. Iconic gestures are defined as having a perceptual resemblance to an object of speech or interaction. Similarly, metaphoric gestures present a perceptual relationship, but instead refer to an abstract object or content (McNeill, 1992).

All of these functions would be potentially useful to an analysis of interactions in art museums, but I wish to focus on iconic gestures as they appear most directly relevant to posing activities. The central feature of iconic gestures is this relationship of visual similarity. For McNeill (1992), the iconicity is dependent on the relationship between the gesture and the accompanying talk. Goodwin (2003) expands this relationship to include both talk and the visible phenomena. That is, there exists a perceptual relationship between a gesture, and either or both of the accompanying speech and phenomena.

These possible relationships of gesture-speech and/or gesture-phenomena have implications for investigations into the role of iconic gestures in multiple learning contexts. For example, young children produce iconic gestures as they develop verbal language (Goldin-Meadow \& Alibali, 2013). Similarly, Hostetter, Alibali, and Kita (2007) experimentally demonstrated this role of gesture in concept formation by having subjects describe images containing various levels of abstraction. They found that subjects gesture more when describing more abstract images and vocalize more when the images are less abstract. In physics classrooms, students were shown to produce iconic gestures while manipulating physical representations in instances where they lack the scientific language and concepts to express themselves verbally (Roth, 2002; Roth \& Lawless, 2002). In categorizing the gestures used by a biology teacher in relation to pictures, Roth and Pozzer-Ardenghi and Roth (2004) demonstrated how iconic gestures function to emphasize particular features of an image.

As evidenced by the breadth of these findings, the label of "iconic gesture" typically does not distinguish between gestural depiction (for others) and gesture as conceptual action (for the self; Streeck, 2009b). The difference between these two forms of action is subtle, but results from observed differences in attentional orientation, with the former being directed toward an addressee and the latter being internally oriented (Streeck, 2009b).

I wish to elaborate on Streeck's two diverging ecologies of iconic gesturing in order to ultimately situate posing as bridging both practices. Conceptual gesturing occurs in social settings, but with the gesture more backgrounded, often without the attention of the gesturer (Streeck, 2009b). A conceptual gesture can be thought of as a psychological tool (Vygotsky, 1978) that is publically and socially visible but also serves the gesturer kinesthetically and visually to organize cognitive action (Streeck, 2009b). This notion reflects a view of gesture as a form of embodied cognition (Wilson, 2002).

Depictive gesturing, in contrast to conceptual gesturing, involves "acts of showing the addressee by movements and postures of the hands what something looks like or is like" (Streeck, 2008, p. 289). This involves the production of gestural pictures that serve to both analyze and represent a particular phenomenon. This is not a process of copying but of interpretation (Streeck, 2008). A variety of methods of gestural depiction have been identified, including but not limited to marking, drawing, and handling. Mimetic gesturing, as one such method of depiction, involves using one's hands or body to represent human bodily action (Streeck, 2009b). Instead of 
pretending that a hand or body represent a thing, mimetic gesture shows doing. If I replicate the figure in Edvard Munch's famous The Scream by placing my hands to my face and pretending to scream, then this may be understood at least in part as a mimetic gesture. Interactions with artwork, though, might not be so straightforward. Would I be depicting the painting or the person shown in the painting? As we see below, contextual factors and orientations in art museum settings require particular considerations of gesture and posing.

\section{Posing With Artwork}

Mimetic gesturing describes many aspects of posing with artwork. However, if mimetic gesture involves depicting and interpreting a body in action, posing with artwork involves the depiction and interpretation of a piece of art, which is itself a depiction of bodily motion by the artist. There is a second level of representation, which creates implications in understanding posing as a meaning making activity. In producing a painting or sculpture of human bodies, an artist is depicting gesture and embedding that work with meaning potentials (Bakhtin, 1986; Streeck, 2009a). Thus visitors posing with artwork are engaged in a reflexive process making meaning about gesture itself. By performing a pose, visitors are implicitly assigning intentionality to the artist, and a pose may be understood as a "posed question" about the potential meanings of a work. The complexities of these embedded meaning potentials in artwork require that we treat posing as a distinct case of gestural practice.

Gesture, thus, is an embodied activity that coordinates both social action and conceptual work. In addition, gesture can be a process of depiction and representation. A single gestural act may serve multiple functions (Kendon, 2004; Streeck, 2009b), but I wish to illustrate how this move across functions occurs. In the data below, I present posing with artwork as a unique embodied meaning making activity related to both depictive gesturing and conceptual gesturing-as shifting between internal and external orientations.

\section{PROJECT BACKGROUND}

This study is part of a larger research project concerned with exploring the use of digital resources to engage young people with the work of Edvard Munch, and with art in general, at the National Museum of Art, Architecture and Design in Oslo, Norway. We designed and installed a project room on the floor of the museum for a period of 8 weeks (Figures 1 and 2). This project room included various digital tools, resources, and activities with the goal of engaging visitors with Edvard Munch through social interaction and with attention to the connection between the location of the room and works of the gallery. This study was inspired by the design experiment method (Brown, 1992; Hoadley, 2004; Krange \& Ludvigsen, 2009) in which an educational technology or activity is designed, implemented, and researched in situ.

The project room consisted of four stations incorporating a variety of technologies and activities designed to support social interaction and meaning making. This article focuses on one of these stations, entitled My Self, in which posing was a central aspect of visitor activity. This station was designed to support visitors in engaging with Munch's self-portraits and the self-portrait genre by encouraging them to explore and re-create the portraits themselves. To understand 


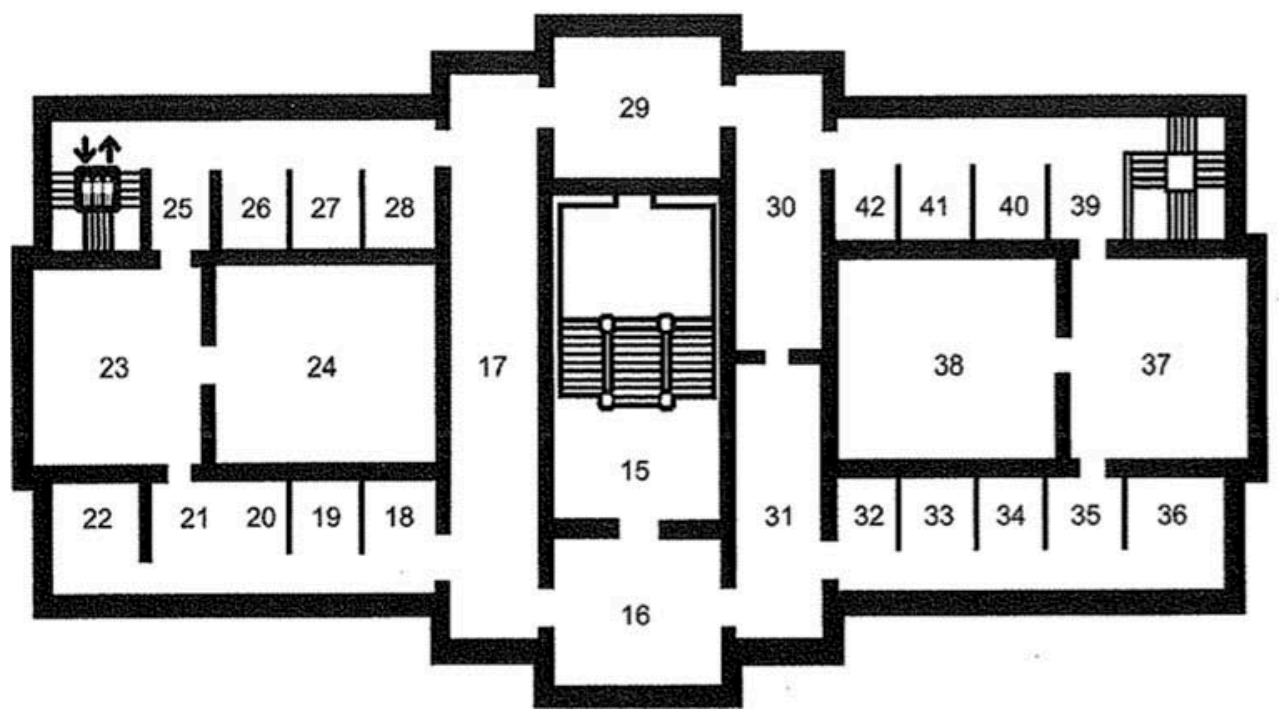

FIGURE 1 Floor plan of the National Museum: The Munch Room Gallery is located in room "24" and the Project Room described here is in room " $22 . "$

the data below, it may be useful to visualize the station activity as mediated by the design (Figure 3).

\section{Exhibit Design}

Station Activity: Visitors read the wall text (A) about Edvard Munch and the self-portrait genre. Visitors then see the task instructions on screen (E) to browse and select a self-portrait (B) by hanging it on the pegs. An embedded RFID tag then identifies the painting to the computer that displays a short text about the work on the display screen (E). After the visitor confirms they wish to use this particular work on touch screen (D), the camera (C) turns on and the visitor is prompted to record a photocomposition recreating the painting. After taking the photograph, the image is displayed on the screen (E) and the visitor is given the options of emailing and sharing the composition on the museum's Flickr stream-through touch screen (D). Finally, a short $30 \mathrm{sec}$ film plays on screen (E) in which a curator highlights an aspect of the work and recommends a related piece of art hanging somewhere in the rest of the gallery.

\section{Data Corpus}

The main body of research data consists of $22 \mathrm{hr}$ of video footage collected during young people's visits to the museum and project room. These visitors consisted of eight small groups of two to four persons 16 to 18 years old. These visitors were recruited through a school English class and 


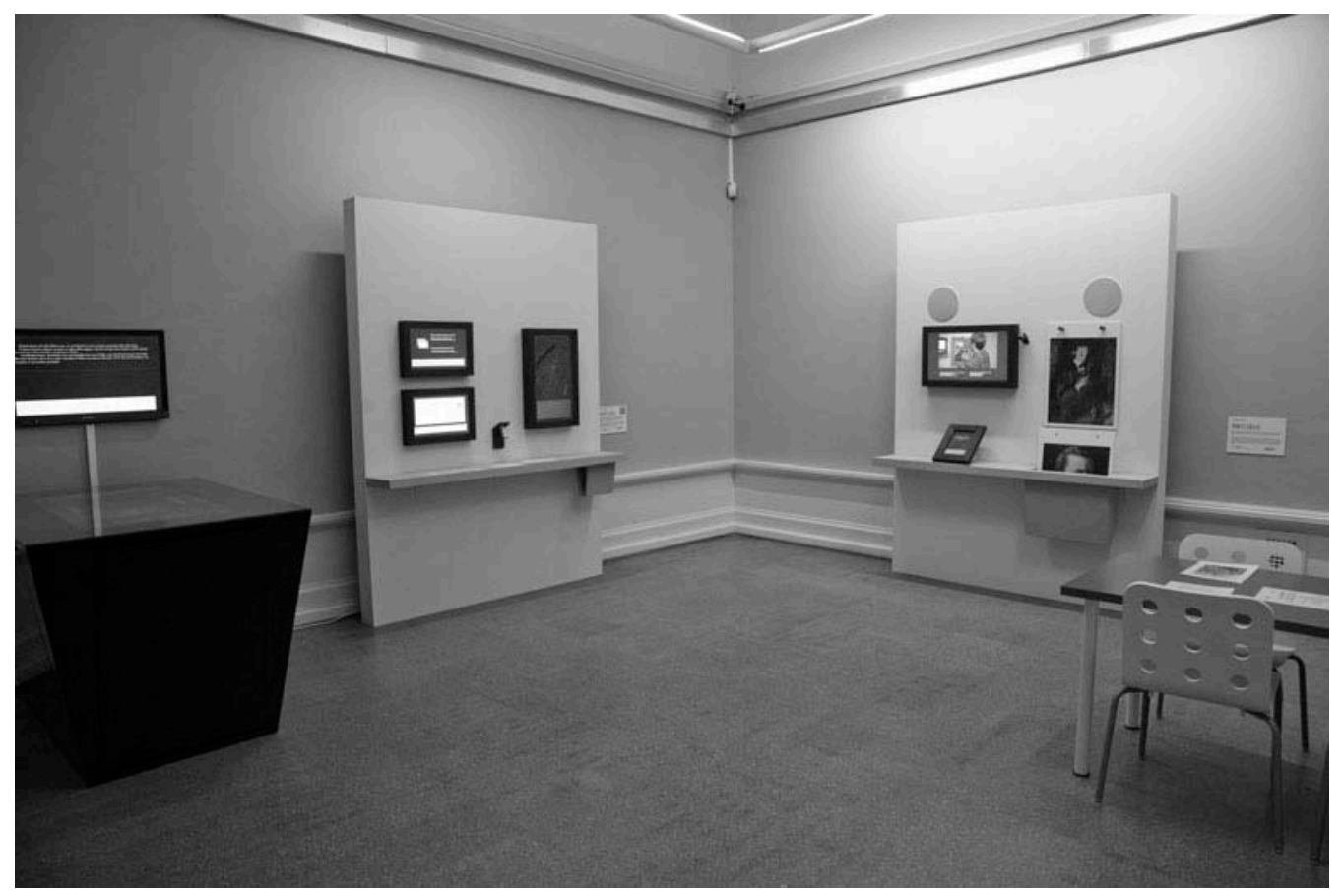

FIGURE 2 Photograph of the installed Project Room.

a separate language program in order to identify English-speaking participants. It was important in the overall study to minimize the role of the "school context" in influencing these students' participation. Accordingly, participants were recruited as volunteers and could invite friends from outside the class to join in their group. These students were asked to form their own small friend groups so as to achieve a comfortable social dynamic. All of the participants were informed that they would be participating in a research project to explore how young people might use technology in an art museum visit.

One member from each group was given a pair of camera glasses to wear and record firstperson video data (Gjedde \& Ingemann, 2008). Some groups were also supplemented with an additional wireless microphone. These students were given simple instructions that they should (a) tour the museum in any order that they liked so long as they visited the project room at some point in their visit, and (b) take on the role of "normal museum visitors" and to try as best as possible to ignore the cameras. One researcher followed each group with a mobile camera for their entire visit. Fixed cameras on tripods also recorded interactions while participants were in the project room. At the end of the visit, brief semi-structured interviews were conducted with each group. The total visit time for these groups lasted between 40 and 75 min with an average of about $1 \mathrm{hr}$.

To summarize, eight small groups of teenage visitors were recorded for their entire visit to the museum with special emphasis placed on interactions in the project room. Three camera angles, 


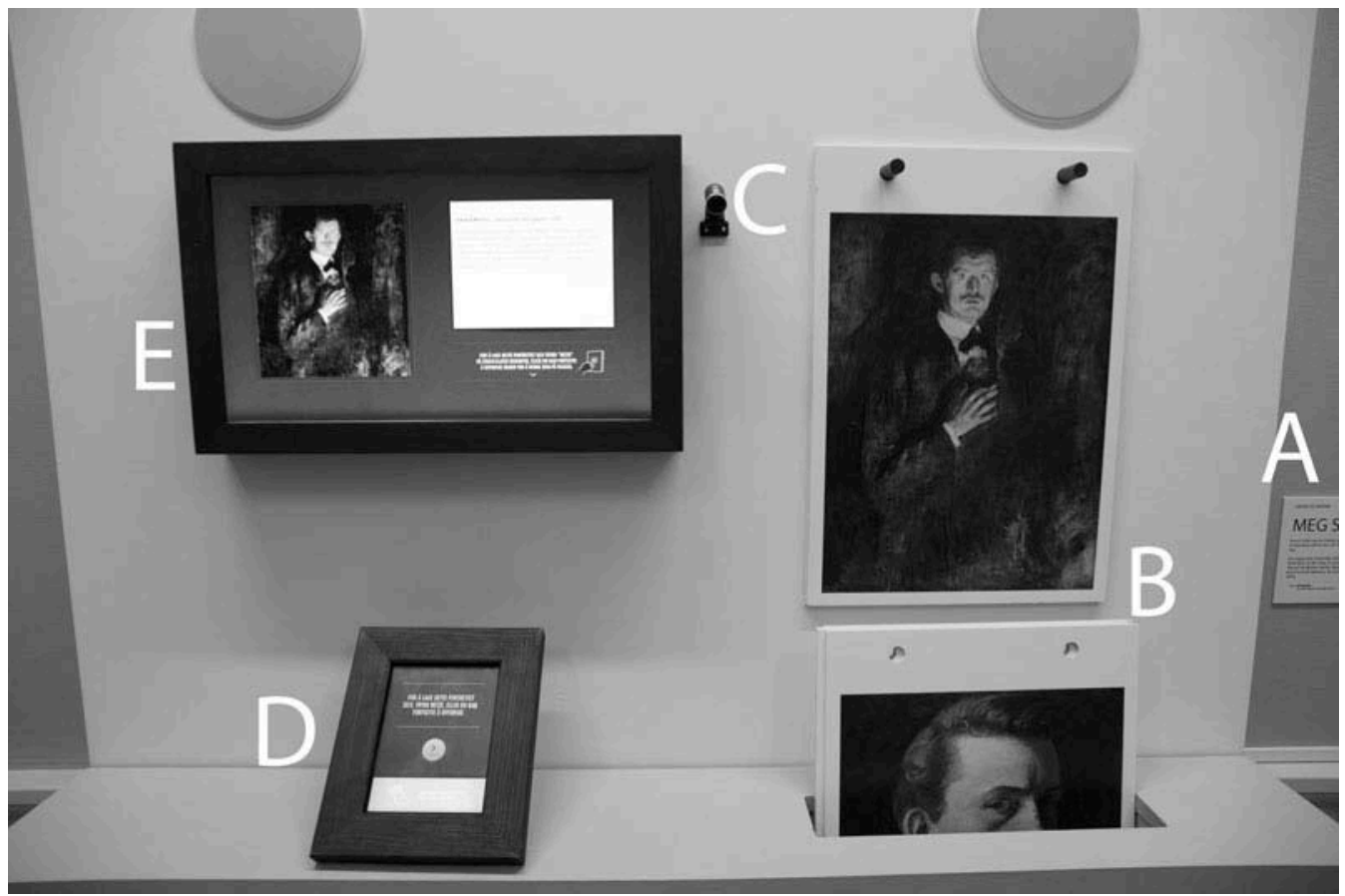

FIGURE 3 Photograph of My Self self-portrait station.

as well as audio, were recorded for these groups. These three camera angles included a mobile researcher camera, a head-mounted glasses camera worn by one member from each visitor group, and two tripod mounted cameras placed in the project room.

\section{ANALYTICAL CONSIDERATIONS AND METHOD}

\section{Art as Knowledge Domain}

As in any field of study, domain specific concepts are needed to interpret meaning making processes. To explore art museum interactions from a perspective of visitor meaning making, I introduce concepts of description and comparison from within the domain of art history and criticism. Although I introduce these concepts as a way to interpret visitor talk, I also show how they are relevant for physical aspects of visitor experiences. These concepts also situate the design of the self-portrait station in relation to the intended learning goals.

One way of conceptualizing interactions with art is through verbal description (related more formally, to explanation and art criticism). Baxandall (1985), in characterizing this type of language in written texts, notes "description is the mediating object of explanation" (p. 1). There are many levels of interpretation embedded in a discussion of a work of art. Language generalizes 
that which is seen, and the act of gazing at an image in a gallery cannot be reproduced by a verbal description (Baxandall, 1985). The activities are different, and the verbal description can better be understood as "a representation of thinking about a picture more than a representation of a picture" (Baxandall, 1985, p. 7). Thus in looking at the data below, the ways in which a visitor describes a work or an image reflect not only what they are seeing but also how they are seeing and interpreting it. Implicit in this interpretive relationship between a work of art and a description is the significance of the presence of the actual image in mediating visitor interaction.

Baxandall characterizes description according to three types of functions: cause, comparison, and effect. These categories may also be useful in the analysis below. Cause words refer to inferences about the artistic process or intention. Comparison words, such as metaphors help characterize features of a work. Third, effect words refer to the impact the work has on the viewer. These concepts characterize the mediational role of language in visitor talk and shape what it is that visitors see and how they talk about it. Initially from the domain of art history, these concepts have been operationalized by Leinhardt and Knutson (2004) in looking at how visitors talk. I build on this work by applying these concepts to physical experiences by looking at how visitors pose and gesture in relation to artwork.

Of the three description concepts previously mentioned, "comparison" is of particular interest. The side-by-side comparison of works of art in an educational setting is credited to Wölfflin, who introduced the practice through lectures over a pair of slide projectors (Bligh \& Lorenz, 2010; Wölfflin, 1915). More recently, Leinhardt and Knutson (2004) coded "comparison talk" in family conversations in art museum visits in relation to interactions with authentic works and reproductions. They found that this comparative talk revealed evidence of careful looking and attention to the detail of artwork. The concept of comparison, and the implication that museum visitors may be able to more thoroughly see and interpret works of art through juxtaposition is central to this study. In the data, we look at how visitors shift their orientation and gaze between works of art and representations. In this case, because the focus of the study is on gesture, this back-andforth shift between the posing friend and the work is of particular significance. This concept also inspired the design of the My Self station, with access to multiple representations, both digital and analogue to support acts of comparison. More generally, comparison is an important concept used by curators in their process of hanging and arranging artwork.

\section{Analytical Method}

Video data from the self-portrait station were first viewed multiple times and broadly sorted. Following this preliminary analysis it became apparent that the phenomena around the visitors' collaborative posing actions were worth investigating further because visitors participated in this station repeatedly, they seemed deeply engaged with the activity, and museum staff were also keenly interested in this activity. I returned to the video data looking for instances of similar posing related talk and behaviors in the main gallery.

The purpose of this study was to identify and explore the emerging phenomenon of posing. I found 18 instances of unprompted posing across five of the eight subject groups in the main gallery. (In some instances the posing was subtle or the camera angle obscured the posing.) In addition, five of the eight groups engaged in prompted posing by participating in the My Self station in the interactive project room. 
Observed instances of unprompted posing included episodes such as a group interacting with Rodin's The Thinker by re-creating his pose, discussing whether he was "really thinking," and what it is that thinking looks like. Another group discussed whether a depicted figure was running or jumping by performing these actions themselves. Yet another member of a group posed with artwork by observing the gaze of the figures in a painting, and moving his own body to where he believed the artist must have been standing. Multiple groups were observed to perform slightly less engaged versions of posing by declaring a version of the expression: "he's like . . " or "she's like" as they mimic the pose or expression of a figure.

In the project room, five groups participated in the posing activity at the My Self station. Several of the groups that did participate performed the task multiple times. In the groups that did not participate, some members displayed nervous laughter after seeing themselves on camera and ended the activity. One group was interrupted by other visitors and did not complete the task. It should also be noted that the instructions to these groups did not require that they participate, only that they "visit the project room."

In general, it appeared as though groups with richer discussions and interactions, and more demonstrated knowledge in the art domain were the groups more likely to engage in posing. The selected episodes presented below were chosen as they clearly illustrate the phenomenon and they were particularly rich interactions that invite a closer analysis.

I present two episodes from a pair of girls' interactions in the museum. The first is of this pair in front of a work in the permanent exhibition (Figure 4) where their acts of posing are unprompted by exhibit design. The second finds them in the project room interacting with the My Friends station just described. The data are presented in a form similar to cartoon panels (Lymer, 2009). The verbal transcript was recorded and chunked according to significant changes

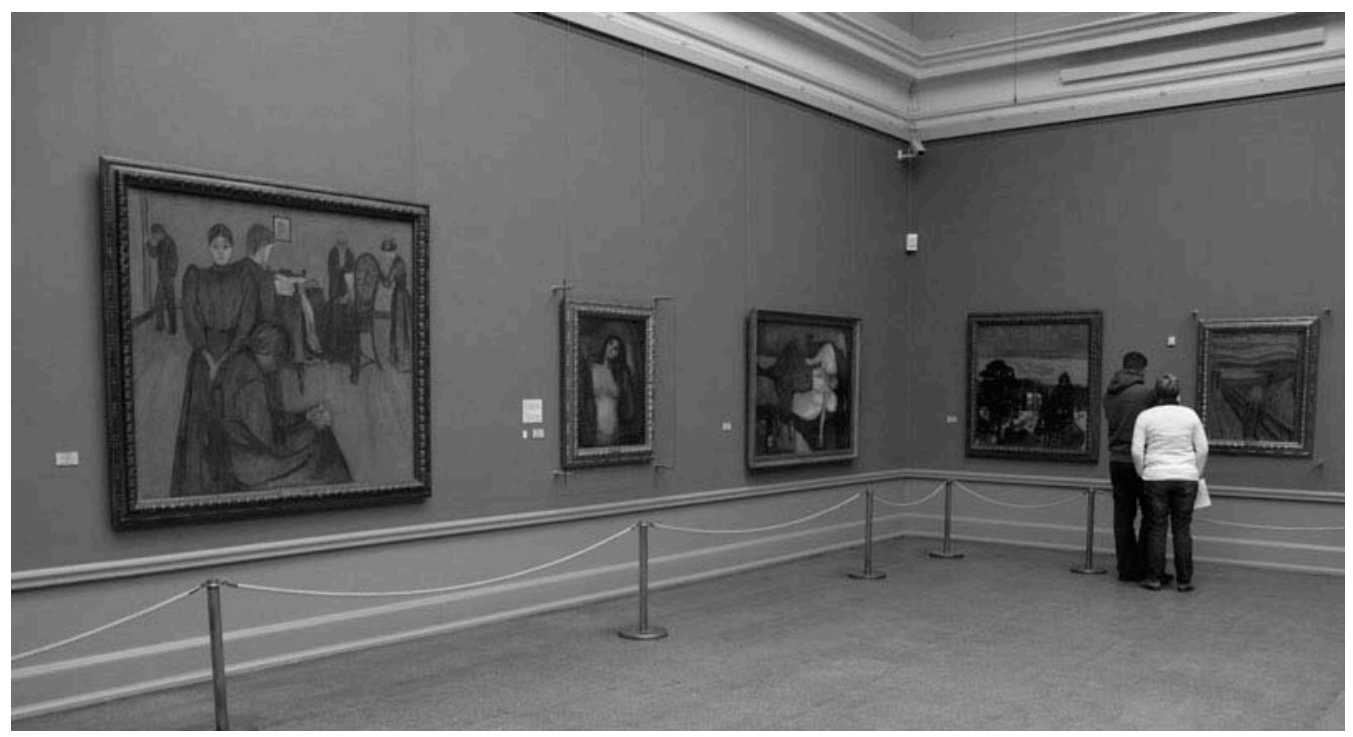

FIGURE 4 Photograph of the main gallery. 
in body positioning and gesture. Below each image is the corresponding transcript, and below the transcript is a description of the participants' body position and action. The analysis that follows describes each episode sequentially and then incorporates concepts from gesture and art in accordance with interaction analysis methods (Derry et al., 2010; Hall, 2000; Jordan \& Henderson, 1995).

\section{Episode 1: Posing in the Gallery}

We begin the first episode just as Mari and Sara have entered the first room in the main floor of the gallery. Mari begins on the left, and Sara on the right in the image. Mari is wearing the camera glasses referenced in the "Data Corpus" section. They are standing in front of a 1936 Charlotte Wankel painting titled Four Artists (Figure 5). Mari leans in to read the label as she approaches the painting, and they have now stood silently for several seconds.

The two gaze at the painting independently for about ten seconds. During this period, Sara begins to position her hands to mimic the central figure in the painting (Figure 6, Panel 1). She then asks Mari, "Why" while displaying this gesture-in effect asking about the significance of the figure's posing. Mari suggests that this pose may signify a "sign of speech" while lifting her hand as though speaking (Panel 2). Mari then shifts her attention to Sara, who lifts up her own hand seemingly modeling Mari (Panel 3).

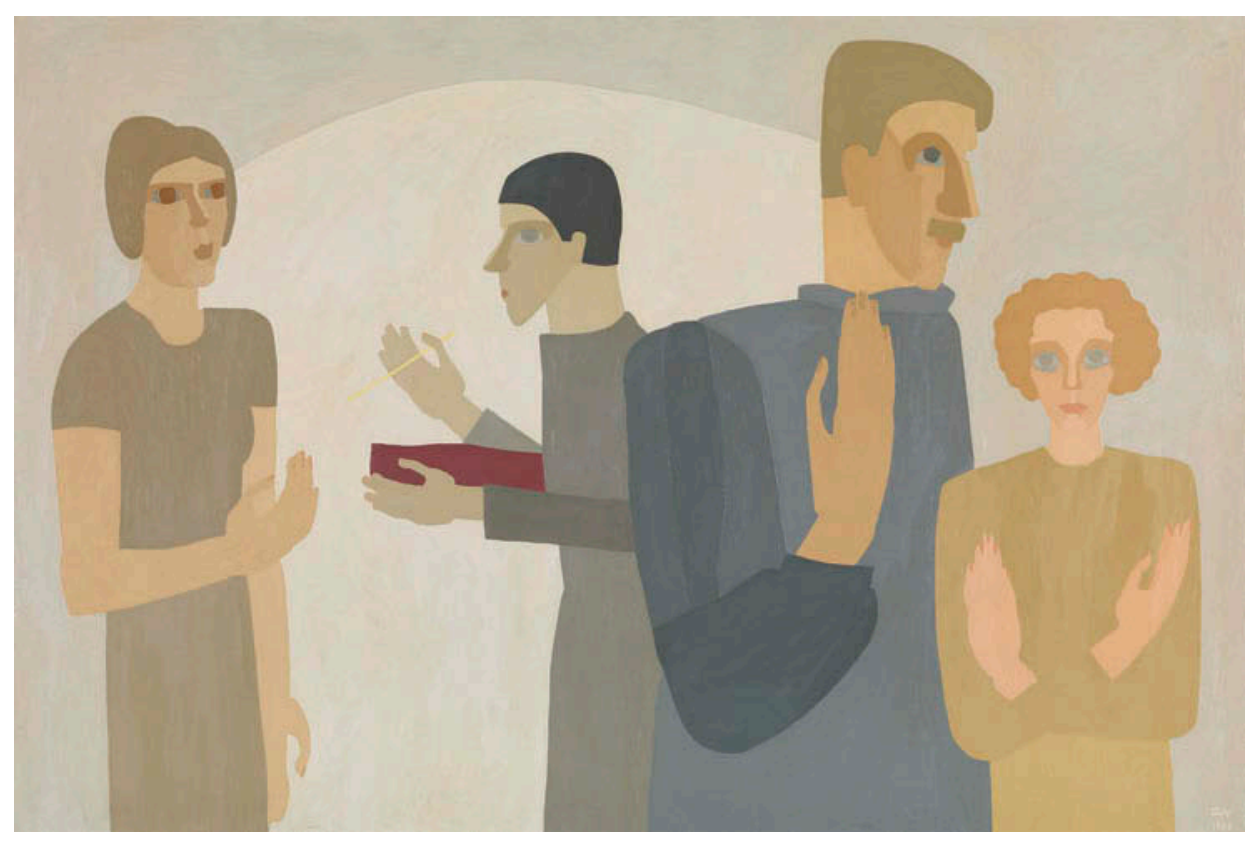

FIGURE 5 Charlotte Wankel. Four Artists (Fire kunstnere, gruppeportrett), 1936. Oil on canvas. The National Museum of Art, Architecture and Design, Oslo (NG.M.04295) (color figure available online). 


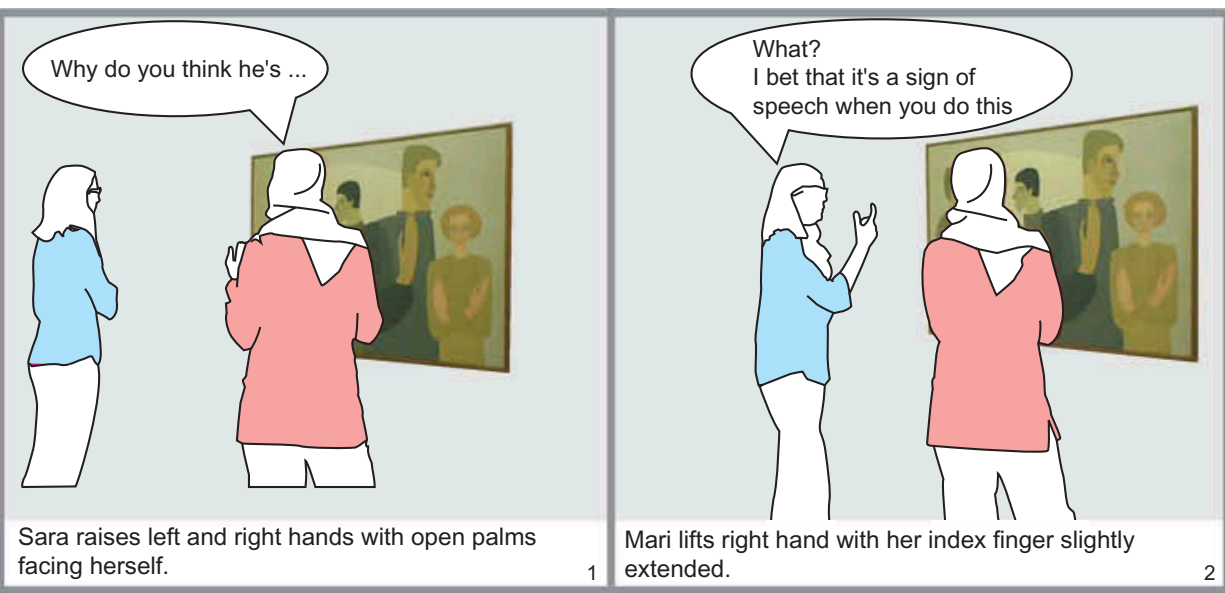

Sara raises left
facing herself.

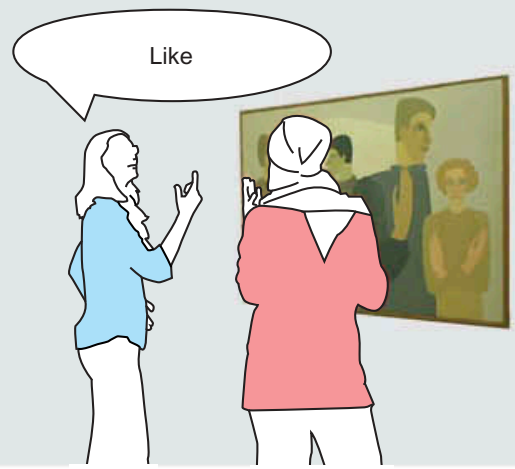

As Mari maintains her gesture, she tilts her head and shifts her gaze to Sara, who similarly lifts up her left left hand.
Mari adjusts her right hand so that the palm faces to her left.

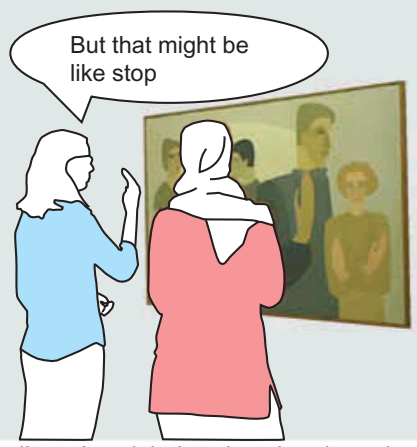

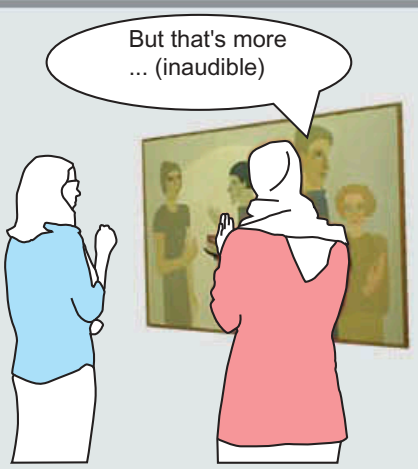

Sara makes a (hidden to us) adjustment to her hand positioning.

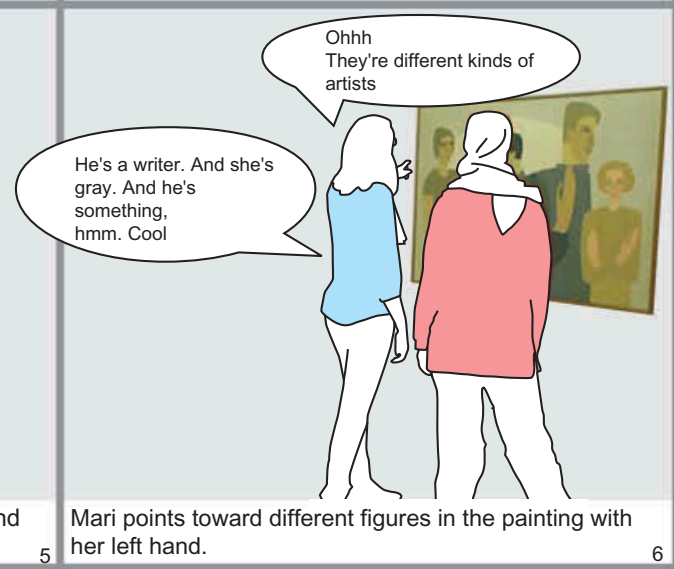

her left hand.

FIGURE 6 Episode 1 (color figure available online). 
Next, Mari returns her attention to the painting and references a different figure while modifying her hand positioning slightly (Panel 4). She suggests that this figure's gesture might depict a command to "stop." Sara then adjusts her own hands again while explaining her correction (Panel 5). Finally, we see Mari come to the conclusion that the different figures in the painting must be representing "different types of artists" as she points to these different figures with her index finger (Panel 6). She identifies one figure as a writer and describes one figure as "gray." Mari concludes the interaction at this painting saying "cool," and the two then leave the room.

In this episode, we see the pair begin by looking at the painting largely independently. Sara begins raising her arms to mimic a figure in the painting seemingly unprompted. It must be noted that this behavior of mimicry is connected with representations of human forms, thus there may be a particular affordance of figurative paintings, an embedded semiotic property that invites such action. We see Sara form this pose before beginning to formulate her question verbally. She lifts her arms and then begins to ask, "Why do you think he's ..." This sequencing is significant as it suggests that Sara begins to pose as part of her own internalization process, as an act of conceptual gesturing (Streeck, 2009b). She re-creates the pose, and only then begins to formulate the question, suggesting that the pose begins as an attempt to make sense of the work for herself. Only then, seeming to seek a causal explanation, she asks the question. This question, though, is articulated with both words and gesture. I would like to emphasize this embodied question as it is serving multiple interesting functions in this interaction.

On one level, we can understand this question as a transition from the interpretive (internally oriented) role of this pose, toward a more communicative (external) role. The very same pose has now become a starting point for discussion. This analysis is also consistent with Roth's (2002) model of gestures linking bodily experience to verbal expression and reflects a transition from conceptual to depictive gesturing (Streeck, 2009b).

Second, we may also understand this same pose as the beginning of an embodied "description" of the work, or more specifically a "cause" word descriptor (Baxandall, 1985). By using the pose to formulate the question in Panel 1, Sara implies an intention by the artist to communicate meaning through the pose of the figure in the painting. Thus this pose can also be understood as embodying a "meaning potential" to be explored as the interaction unfolds (Bakhtin, 1986). Third, the same pose also serves an entry point for acts of comparison (Leinhardt \& Knutson, 2004). As Sara's pose has now become a shared representation of the figure in the painting, the pair is now able to focus on and explore features of the work by comparing the work to the pose in the form of an embodied representation.

As the interaction unfolds, we see Sara mimic the gesture of Mari in Panel 3, seemingly in an attempt to join Mari's interpretive process. Sara doesn't simply accept Mari's suggestion; she performs the gesture seemingly to test the gesture as a representation of "speech." This testing may serve as another conceptual gesture (Streeck, 2009b) to internalize this particular explanation. In this instance, Sara's gesture is functioning simultaneously as a part of her cognitive process but also as a demonstration to Mari that she acknowledges Mari's suggestion. This pattern repeats in Panel 4 with Mari offering a gestural explanation of a sign for "stop." This time, though, we see Sara adjust the gesture as a possible challenge to Mari's explanation. Sara claims, "that's more ..." with her modified gesture serving to again complete the sentence.

In Panel 6, the gestures shift from iconic to deictic (McNeill, 1992) as Mari begins pointing toward figures in the painting rather than mimicking the poses of the figures. When Mari states 
"ohhhh, they're different kinds of artists," we see her connect the meaning potentials embedded in her understanding of the symbolism of the posed figures with the resource of the painting's title on the label (Four Artists). The initial posed "cause" question by Sara ("why do you think he's . . .") leads the pair on a trajectory that makes the painting's title a relevant resource. Thus the posing gestures by this pair of visitors, in coordination with the work and its title, play several important and related roles in their meaning making activity. After beginning as an unprompted pose to find meaning in the artwork, the pair's constantly adjusting poses become an embodied representation of their evolving understanding. These poses support both social processes of coordination and processes of internalization.

\section{Episode 2: Posing at the My Self Station (Project Room)}

Although the first episode demonstrated multiple aspects of unprompted posing in relation to meaning making processes, we now turn to an instance of exhibit-prompted posing to explore these processes more deeply. This episode begins with Mari and Sara in the interactive project room, having already gone through one round of the self-portrait activity. Mari has made a selfportrait, assisted by Sara, and they have now switched roles so that Sara will make a self-portrait. They have selected a print to work with (Self-Portrait with a Cigarette, 1895; Figure 7), and in fact they have already had an interaction with this work in the main gallery. In this earlier conversation, Mari told Sara that in an earlier visit to the museum she had a discussion about the symbolic meaning of Munch's hand holding a cigarette in the center of the painting. She suggests that his hand and cigarette might also represent a paintbrush and his identity as an artist. They do not reference this conversation specifically in the following episode, but they do emphasize the placement of his hand. The episode begins with the reading of a digital text about this particular work.

Sara begins by calling attention to the digital text. She points as she reads a description of Munch's expression as "a little surprised." Mari then moves to also read the text. Next, the two advance to the photo-taking portion of the activity and the webcam is activated. Sara begins to position herself (Figure 8, Panel 2) and asks if there is something for her to hold, presumably resembling Munch's held cigarette. In response, Mari looks at Sara's hand and moves to reposition it closer to her body. As she does this, she shifts her gaze to the screen where she can see the image of Sara next to the image of Munch. Sara then states, "it has to be the same size," probably referring to the relationship between the relative positioning of herself in the image and Munch in his painting (Panel 4). Mari responds by saying that "you need to be taller." Sara, in turn, becomes "taller" by standing on her toes. Mari confirms this adjustment (Panel 5).

Sara again declares she is not ready for the picture and then calls attention to her hand (Panel 6). Mari explains how she believes Sara's thumb needs to be positioned by first demonstrating with her own hand. Then, Mari moves to physically adjust Sara's hand (Panel 7). Mari shifts from gazing directly at Sara's hand to seeing how this adjustment displays on the screen (Panel 8). Finally, Mari models Munch's expression, calling Sara's attention to her face as she says, "do this" (Panel 9). As the photograph is taken and displayed (Panel 10), Mari and Sara respond with laughter and Sara states that she doesn't believe her expression represents "surprise" as she intended, and that she would like to try again. 


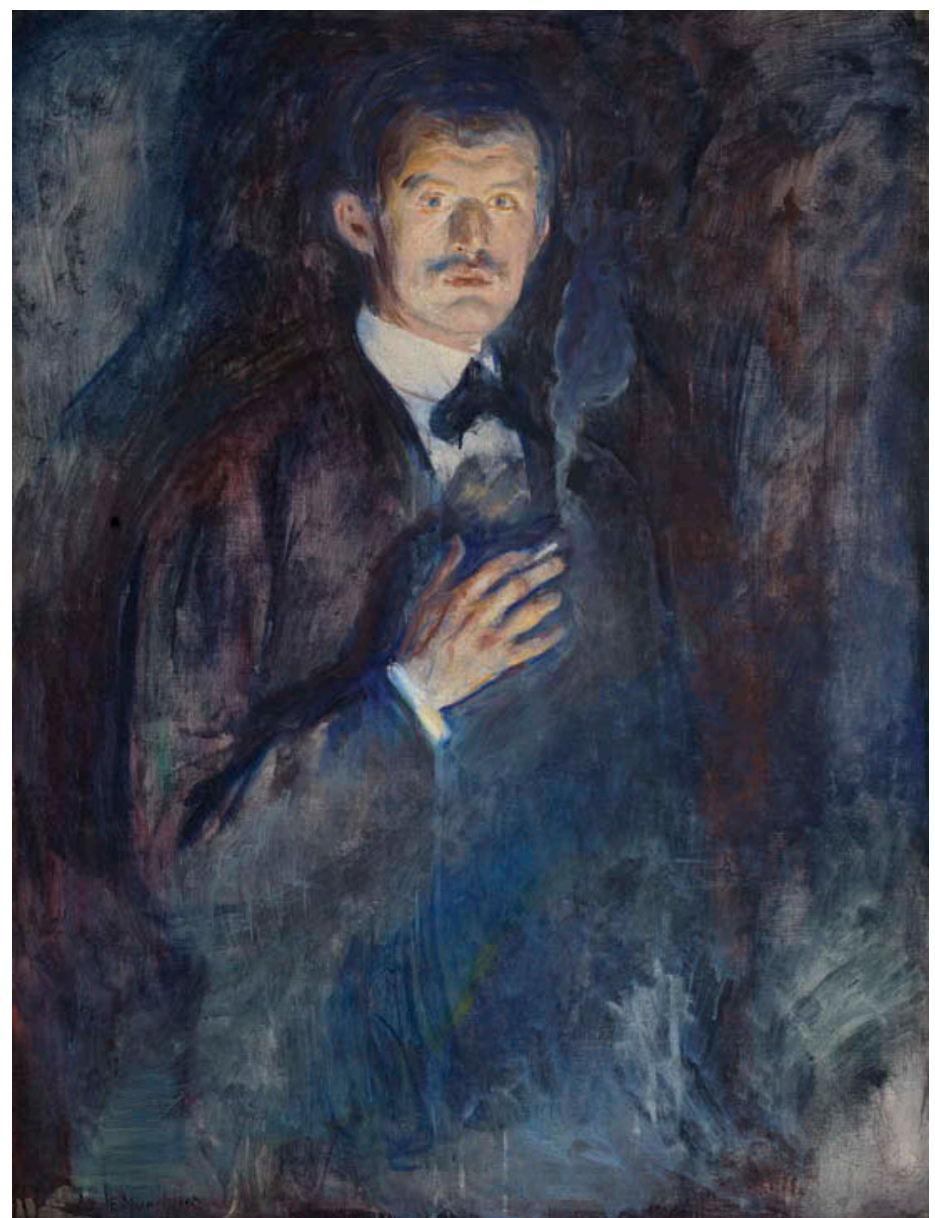

FIGURE 7 Edvard Munch. Self-Portrait with a Cigarette (Selvportrett med sigarett) 1895. Oil on canvas. 110.5 x $85.5 \mathrm{~cm}$. Nasjonalgalleriet, Oslo (NG.M.00470) (color figure available online).

There are several aspects of this interaction that I wish to highlight. First, we see the pair making use of the digital text as a joint resource, noting that Munch's expression is one of "surprise." This text then, functioning as a "descriptive text," informs what it is they see in the painting (Baxandall, 1985). This description, and the notion of surprise, thus becomes a salient feature of the work guiding the interaction. In fact, Sara actually uses this concept to evaluate her success in recreating the portrait as she states, "I don't think that's surprised [ . . . ]" (Panel 10).

Second, we can also look at this interaction to identify the multiple acts of comparison that, in relation to the posing gestures in particular, function as central to the pair's meaning making process. We see evidence of comparison in shifts in attention between the poses of both visitors, the on-screen image of the visitor, and representations of the work itself. In Panels 2 to 4, we see 


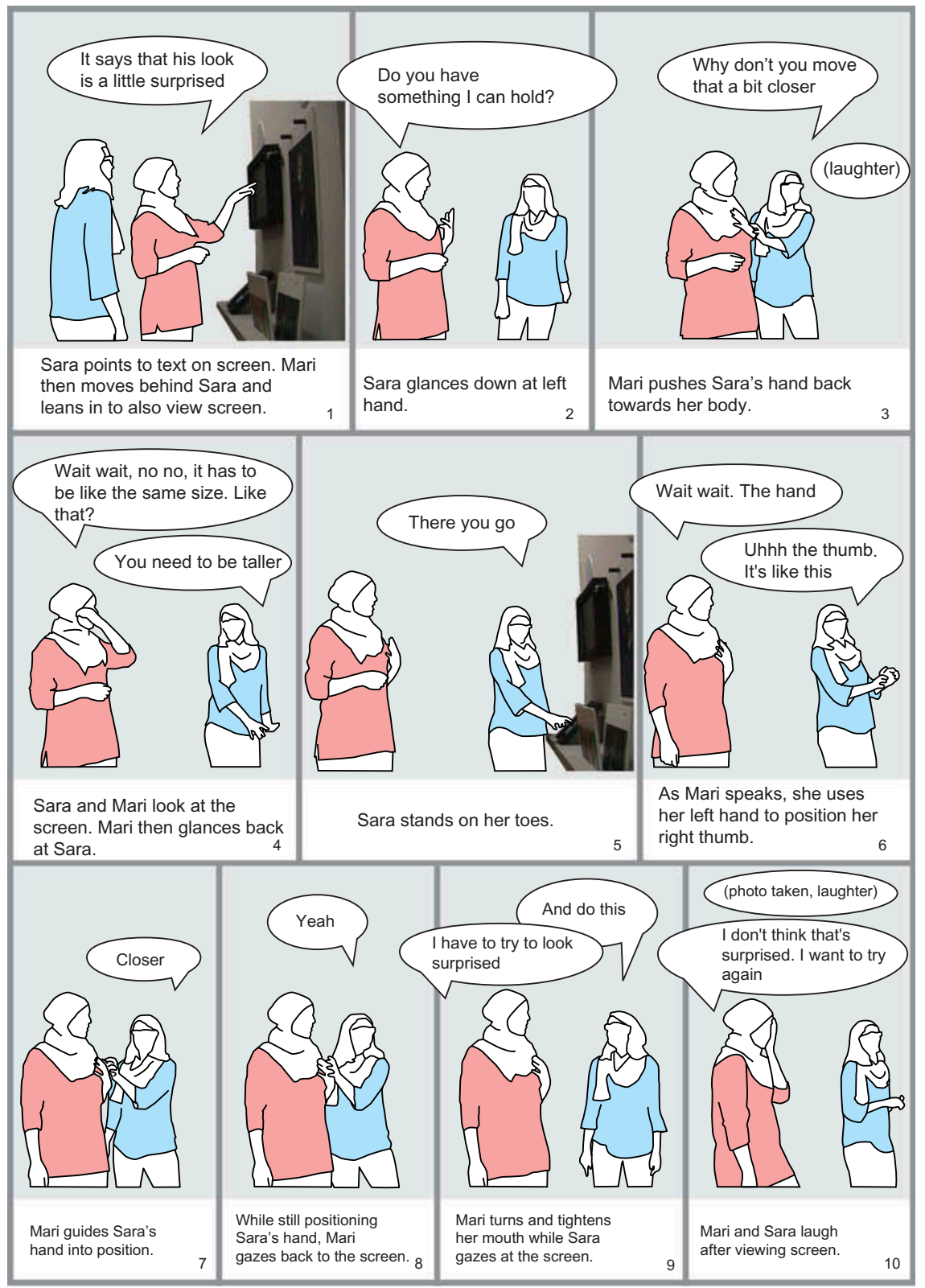

FIGURE 8 Episode 2 (color figure available online).

Sara shift her gaze from Mari's pose, then to the screen - then back to Mari, and then back to the screen again. In Panels 6 to 8, we see Mari shift attention from her own gesture, back to Sara's pose, and then back to the screen again. It is through these comparisons that the visitors are able to perceive and make relevant, particular features and qualities of the work. 
Third, multiple features of the work emerge as salient through these comparisons between the pose and the work. For example, in Panel 4, notions of composition become a focus of attention as Sara talks about needing to be the "same size" prompting Mari to direct her to "be taller." This exchange shows their awareness of Munch's position in the frame. Similarly, Munch's expression is made relevant at the start of the episode but returns again in Panel 10 as Mari evaluates her portrait. This evaluation and the saliency of expressing surprise develop in part through the comparison between the visitors' own poses and Munch's. Also, the cigarette in Munch's hand becomes a relevant feature as the pair re-creates this particular gesture. Multiple iterations of gesture and adjustment, coordinated between the pair, suggest that the pair really is paying close attention to this cigarette and the specific manner in which Munch holds it. In any case, we thus we have the following aspects of the painting made relevant in this activity: expression, composition, gesture.

Fourth, just as in the first episode, we can look at the relationship between these internalization and externalization processes of meaning making. In Panels 6 and 7 we see Mari modeling the particular cigarette gesture on her self before moving to physically position Sara. Mari first notices an inconsistency (through comparison!) between Mari's hand and that of Munch. She has difficulty articulating this difference to Sara, however, so while looking at her own hand, she forms the particular gesture. At this point, we can understand Mari's small pose as a conceptual gesture used to articulate an aspect of the work (Streeck, 2009b). At this moment, however, ("it's like this"), the pose becomes mimetic in function and shifts toward a more communicative role that allows the pair to coordinate their actions (Streeck, 2009b). Thus, once again a particular pose can be understood as being oriented both internally and externally.

Embedded in this discussion is the iterative nature of the pair's activity. They are performing a kind of social self-correction as, for example, Mari physically adjusts Sara's pose in Panels 3 and 7. This process of adjustment, in particular through acts of comparison, is central to the pair's meaning making as they refine their gestural articulations.

Finally, it should also be noted that we see strong evidence of general engagement and enthusiasm. This is the second round of the activity; thus they enjoyed the task enough to do it again. Also, we see them laughing repeatedly. Perhaps even more significantly, we see Sara repeatedly tell Mari to wait in order to keep making adjustments to her composition-in order to "perfect" it. This attention to detail suggests that they are deeply engaged with the task.

\section{DISCUSSION}

\section{The Posing Process: A Pattern Emerges}

In both episodes we see a particular cycle or pattern emerge. First, an initial interest in a work leads to a visitor's initial pose mimicking a figure in the painting. This prompt might be explained as an inherent affordance of figurative artwork that invites mimicry (Streeck, 2009a). Or, as in the second episode, a prompt as a task embedded in the activity itself. Regardless, this pose may be seen as a starting point, or as an initial "posed question." From this pose, the visitors have now gained both a new representation of the artwork in the form of their embodied understanding and a focal point for joint attention between the two visitors. They are now able to make a comparison between the work and this pose. These acts of comparison, in turn, lead particular features 
of the work to come into focus, in the form of differences between representations. As this new feature is made relevant, the visitors begin to focus on it and engage with it. From this focused describing and comparative work, visitors then make adjustments to their pose. This, in turn, provides a (slightly) new pose or representation with which to begin this cycle again. More simply, this process can be depicted as the iterative cycle: POSE $\rightarrow$ COMPARISON $\rightarrow$ FOCUS $\rightarrow$ ADJUSTMENT.

\section{Posing as Internally and Externally Oriented}

This cycle may also be discussed in relation to dialectic processes of internalization and externalization. At each step, the pose functions to internalize meaning for a visitor (Vygotsky, 1978). But at the same time, this pose is a shared and external representation, and thus advances the social aspects of this cycle. That is, a pose can simultaneously be understood as an embodied articulation of an individual's conceptual work, as well as a shared representation for social coordination and discussion. Indeed, as Streeck (2009b) notes, gestures may be considered

as a kind of artifact, a cognitive artifact, that enable flexible, dynamic, and multimodal representations which operate both inter-psychologically, that is, in the intersubjective, public realm, and intrapsychologically, that is, in the realm of individual imagination and thought. Cognitive artifacts—or psychological tools (Vygotsky 1978) - mediate cognition. (Streeck, 2009b, p. 173)

The main point that I wish to highlight is that posing seems to serve these two functions. They serve as a part of museum visitors' interpretive process, helping them articulate a description, response, interpretation, or experience of a particular piece of art. In this way, the gesture functions as a part of the internalization process, as an act of conceptual gesturing (Streeck, 2009b). The other function is more externally oriented as a depictive gesture (Streeck, 2009b). These poses establish a joint reference point by which a group of visitors is able to make comparisons. From an institutional perspective, the group context may also make these posing gestures more socially acceptable than if they came from an individual museum visitor.

It is the relationship between these two functions that I believe to be particularly significant. As the visitor articulates her own understanding through gesture, she is also visible to and interacting with a friend. So the posing visitor is able to make adjustments through feedback by comparing her own body to the work just as the friend is able to suggest adjustments by comparing the friend's body or pose to the work. In turn, this internalization process by the posing visitor actually becomes a communicative process, informed by collaboration. Further, we can also say that this embodied action by the "poser" is a part of the interpretive process of the friend. Thus these two processes of interpretation and social coordination are actually quite intertwined. In Figure 9, we can see internal and external orientations weaving through the iterative cycle of this posing activity. This model depicts only the steps of this cycle and is not a representation of the entire activity of posing.

We may now illustrate this cycle through our preceding episodes. In the first episode, we saw Sara's initial search for cause prompt her to mimic the gesture of the figure in the painting in an attempt to understand the meaning of this particular pose. At this point, her pose may be understood at this internal level. However, she then turns this pose into a question-as an external representation to be shared in her social setting. This prompts the cycle to begin as we start with 


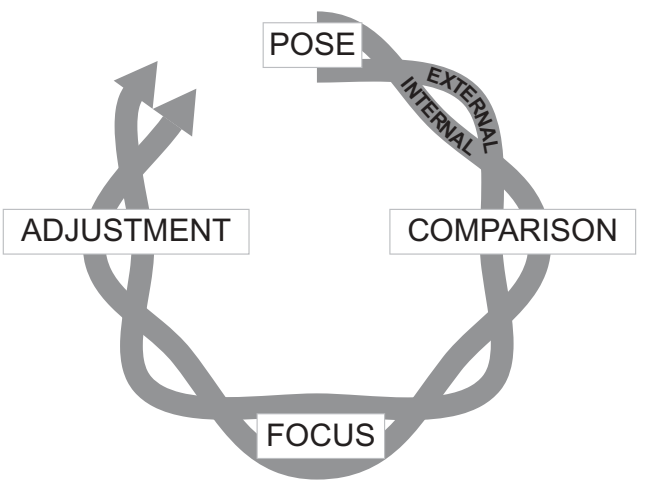

FIGURE 9 Posing cycle.

Sara's "posed question" ("Why do you think he's ... "). This prompts Mari to compare Sara's pose to that of the figure in the artwork, and in turn offer up her own posed representation. This comparison allows the pair to focus on the embedded meaning of figure's gesture in the work. Mari suggests that the figures gesture implies an act of "speech." This emerging meaning very quickly becomes a new opportunity for comparison, and a small physical adjustment is made in turn with a new symbolic meaning. Maybe the gesture actually means "stop," Mari offers. The cycle repeats as they each make adjustments to their posed representations ultimately finding meaning by connecting the title of the work to the meaning potentials of the posed gestures.

In the second episode, quite similarly, we see an initial pose (in this case prompted by the designed activity). This initial pose leads to multiple iterations of Gesture, Comparison, Focus, and Adjustment. First, the hand holding the cigarette is relevant. Then through more rounds of comparison, Munch's "height" and surprised expression emerge as relevant features. At one point, Mari, in directing Sara, lacks the ability to articulate the necessary adjustment to Sara. She first gestures herself while looking at her own hand to internalize this representation. She then turns this gesture into a demonstration for Sara, enacting the social role of the same pose in this process.

\section{Posing and Visitor Meaning Making}

It is through this cycle of pose, comparison, focus, adjustment that meaning emerges. Posing is also related to talk, and visitors are talking and posing as they interact with art and each other. That is, we may understand meaning making as the progression of this posing cycle in coordination with dialogical processes.

In a sense, the pose can be understood as an embodied interpretive space that allows the pair to both perceive and find meaning in the work. Within this workspace, we see evidence of acts of comparison, description, and perhaps of most interest these acts are revised and adjusted through iterations of the pose. It is these iterations of the posing cycle, in conjunction with turn taking by the group, that allow us to see the pose functioning internally and externally. These adjustments reflect a developmental aspect of interaction. Meaning develops through this posing cycle until the group arrives at a shared interpretation with which they are comfortable. Collectively, this 
cycle of posing and adjusting, as a reflection of individual and social processes, constitute an important aspect of the visitor meaning making process.

The posing gestures are of course not the only resource for meaning making. We also see that texts, even those as simple as the title of a work, are brought up and made relevant in the interactions. More important, the pieces of art themselves are embedded with meaning potentials and mediate these interactions.

\section{CONCLUSION}

Sociocultural research concludes that language is a central cultural tool for visitor meaning making in museums. We have now seen the processes through which gesture also functions as one of these cultural tools, and that the use of gesture in coordination with language mediates visitor meaning making. In describing and exploring this posing process, we can expand our understanding of art museum meaning making processes. In addition to talk, we also must consider the ways visitors use their bodies through actions such as posing. It is in the interaction between gestures and talk that unique meanings arise.

Second, research into gesture in general often focuses on either the communicative or conceptual roles of such gesture. Using art museums as a setting, this article has illustrated the complex relationship between these aspects of posing gestures in order to deepen our understanding of the roles that gesture plays in meaning making interactions in general. Just as children learn to count using their fingers as a part of their cognitive development (e.g., Fischer, 2008; Wilson, 2002), we might consider museum visitors' posing as learning to interpret art. These poses, though, are also socially situated and used collaboratively as a group resource. The process of making meaning through posing consists of a dialectic movement between communicative and conceptual work.

We can also begin to consider broader implications for museum institutions, exhibition design, and visitor experiences. In addition to language, knowing that there is a strong physical aspect to visitor meaning making suggests that museums should consider spaces and resources in new ways. The features of particular works that invite posing (e.g., the painting figures in Episode 1) invite further exploration in order to facilitate the design and arrangement of mediating resources. Just as one barrier to understanding in art museums may be the institutional rule of "no loud talking," similarly "loud movements" may also be seen as making an important contribution to the visitor experience. As such, a tacit restriction on posing may be at odds with meaning making processes. Interactive exhibits, such as the My Self station described in this article, may be further developed to make constructive use of such visitor posing.

More generally, we can begin to see tourists posing for a photo in front of a statue as an entry point or opportunity for a deeper meaning making interaction. Understanding this interrelatedness between social and psychological aspects of posing and gesture further demonstrates the complexity of our interactions with cultural artifacts.

\section{ACKNOWLEDGMENTS}

This research is made possible through the CONTACT project, financed by The Research Council of Norway. I would especially like to thank the students and museum visitors who participated in this study, as well as Matthew Lucas for his assistance. I also thank Anne Qvale and Frithjof 
Bringager at the National Museum of Art, Architecture and Design as well as Janne Fredly. I'm thankful to Jeremy Touissaint, Anthony Perritano, and the rest of the EngageLab for their many design contributions in the project room. In particular, I also thank Palmyre Pierroux as well as Ingeborg Krange and Sten Ludvigsen for guidance in this study in addition to the rest my colleagues in the InterMedia research group.

\section{REFERENCES}

Alexander, J., Barton, J., \& Goeser, C. (2013). Transforming the art museum experience: Gallery One. Paper presented at the MW2013: Museums and the Web 2013, April 17-20, Portland, OR.

Allen, S. (2002). Looking for learning in visitor talk: A methodological exploration. In G. Leinhardt, K. Crowley, \& K. Knutson (Eds.), Learning conversations in museums (pp. 259-303). Mahwah, NJ: Erlbaum.

Ash, D. (2004). How families use questions at dioramas: Ideas for exhibit design. Curator: The Museum Journal, 47, 84-100.

Bakhtin, M. M. (1986). Speech genres and other late essays. Austin, TX: University of Texas Press.

Baxandall, M. (1985). Patterns of intention: On the historical explanation of pictures. New Haven, CT: Yale University Press.

Bligh, B., \& Lorenz, K. (2010). The rhetoric of multi-display learning spaces: Exploratory experiences in visual art disciplines. Seminar.net, 6(1).

Brown, A. (1992). Design experiments: Theoretical and methodological challenges in creating complex interventions in classroom settings. The Journal of the Learning Sciences, 2, 141-178.

Cheville, J. (2006). The bias of materiality in sociocultural research: Reconceiving embodiment. Mind, Culture, and Activity, 13, 25-37.

Derry, S. J., Pea, R. D., Barron, B., Engle, R., Erickson, F., Goldman, R., et al. (2010). Conducting video research in the learning sciences: Guidance on selection, analysis, technology, and ethics. Journal of the Learning Sciences, 19, 3-53.

Dourish, P. (2004). Where the action is: The foundations of embodied interaction. Cambridge, MA: MIT Press.

Falk, J. H., \& Dierking, L. D. (2000). Learning from museums: Visitor experiences and the making of meaning. Lanham, MD: Altamira Press.

Farr, W., Price, S., \& Jewitt, C. (2012, February). An introduction to embodiment and digital technology research: Interdisciplinary themes and perspectives (NCRM Working Paper). National Centre for Research Methods. Retrieved from http://eprints.ncrm.ac.uk/2257/4/NCRM_workingpaper_0212.pdf

Fischer, M. H. (2008). Finger counting habits modulate spatial-numerical associations. Cortex, 44, 386-392.

Gjedde, L., \& Ingemann, B. (2008). Researching experiences: Exploring processual and experimental methods in cultural analysis. Newcastle Upon Tyne, UK: Cambridge Scholars Press.

Goldin-Meadow, S., \& Alibali, M. W. (2013). Gesture's role in speaking, learning, and creating language. Annual Review of Psychology, 64, 257-283.

Goodwin, C. (1986). Gestures as a resource for the organization of mutual orientation. Semiotica, 62, 29-49

Goodwin, C. (2000). Action and embodiment within situated human interaction. Journal of Pragmatics, 32, $1489-1522$.

Goodwin, C. (2003). Pointing as situated practice. In S. Kita (Ed.), Pointing: Where language, culture and cognition meet (pp. 217-241). Mahwah, NJ: Erlbaum.

Hall, R. (2000). Video recording as theory. In D. Lesh \& A. Kelley (Eds.), Handbook of research design in mathematics and science education (pp. 647-664). Mahwah, NJ: Erlbaum.

Hoadley, C. M. (2004). Methodological alignment in design-based research. Educational Psychologist, 39, $203-212$.

Hohenstein, J. (2006). Discussing the role of conversation in learning at informal science institutions. San Francisco, CA: Center for Informal Learning and Schools.

Hostetter, A. B., Alibali, M. W., \& Kita, S. (2007). I see it in my hands' eye: Representational gestures reflect conceptual demands. Language and Cognitive Processes, 22, 313-336.

Hurwitz, A., \& Day, M. (2007). Children and their art: Methods for the elementary school. Belmont, CA: Thomson.

Jaworski, A., \& Thurlow, C. (2009). Gesture and movement in tourist spaces. In C. Jewitt (Ed.), Routledge handbook of multimodal discourse analysis (pp. 253-262). New York, NY: Routledge. 
Jordan, B. \& Henderson, A. (1995). Interaction analysis. The Journal of the Learning Sciences, 4, 39-103.

Joy, A., \& Sherry, J. F., Jr. (2003). Speaking of art as embodied imagination: A multisensory approach to understanding aesthetic experience. Journal of Consumer Research, 30, 259-282.

Kendon, A. (1983). Gesture and speech: How they interact. Nonverbal Interaction, 11, 13-45.

Kendon, A. (2004). Gesture: Visible action as utterance. New York, NY: Cambridge University Press.

Knutson, K., \& Crowley, K. (2010). Connecting with art: How families talk about art in a museum setting. In Instructional explanations in the disciplines (pp. 189-206). New York, NY: Springer.

Krange, I., \& Ludvigsen, S. (2009). The historical and situated nature design experiments: Implications for data analysis. Journal of Computer Assisted Learning, 25, 268-279.

Lakoff, G., \& Johnson, M. (1999). Philosophy in the flesh: The embodied mind and its challenge to Western thought. New York, NY: Basic Books.

Leder, H., Belke, B., Oeberst, A., \& Augustin, D. (2004). A model of aesthetic appreciation and aesthetic judgments. British Journal of Psychology, 95, 489-508.

Leinhardt, G., Crowley, K., \& Knutson, K. (2002). Learning conversations in museums. Mahwah, NJ: Erlbaum.

Leinhardt, G., \& Knutson, K. (2004). Listening in on museum conversations. Lanham, MD: Rowman Altamira.

Lymer, G. (2009). Demonstrating professional vision: The work of critique in architectural education. Mind, Culture, and Activity, 16, 145-171.

McNeill, D. (1992). Hand and mind: What gestures reveal about thought. Chicago, IL: University of Chicago Press.

Merleau-Ponty, M. (1974). Phenomenology: Language and society. Portsmouth, NH: Heinemann. (Original work published 1945)

Munch, E. (1895). Self-portrait with a cigarette [Selvportrett med sigarett]. Oil on canvas. $110.5 \times 85.5 \mathrm{~cm}$. Nasjonalgalleriet, Oslo (NG.M.00470).

Pierroux, P. (2003). Communicating art in museums. Journal of Museum Education 28, 3-7.

Pierroux, P. (2005). Dispensing with formalities in art education research. Nordisk Museologi, 2, 76-88.

Pierroux, P. (2006). Meaning, learning, and art in museums: A situated perspective (Unpublished doctoral dissertation). University of Oslo, Oslo, Norway.

Piscitelli, B., \& Weier, K. (2002). Learning with, through, and about art: The role of social interactions. In S. Paris (Ed.), Perspectives on object-centered learning in museums (pp. 121-151). Mahwah, NJ: Erlbaum.

Pozzer-Ardenghi, L., \& Roth, W.-M. (2004). Photographs in lectures: Gestures as meaning-making resources. Linguistics and Education, 15, 275-293.

Roth, W. M. (2002). From action to discourse: The bridging function of gestures. Cognitive Systems Research, 3, 535-554.

Roth, W. M., \& Lawless, D. V. (2002). How does the body get into the mind? Human Studies, 25, 333-358.

Schauble, L., Leinhardt, G., \& Martin, L. (1997). A framework for organizing a cumulative research agenda in informal learning contexts. Journal of Museum Education, 22, 3-7.

Stainton, C. (2002). Voices and images: Making connections between identity and art. In G. Leinhardt, K. Crowley, \& K. Knutson (Eds.), Learning conversations in museums (pp. 213-257). Mahwah, NJ: Erlbaum.

Streeck, J. (2008). Depicting by gesture. Gesture, 8, 285-301.

Streeck, J. (2009a). Depicting gestures: Examples of the analysis of embodied communication in the arts of the West. Gesture, 9, 1-34.

Streeck, J. (2009b). Gesturecraft: The manu-facture of meaning (Vol. 2). Amsterdam: John Benjamins.

vom Lehn, D., Heath, C., \& Hindmarsh, J. (2001). Exhibiting interaction: Conduct and collaboration in museums and galleries. Symbolic Interaction, 24, 189-216.

vom Lehn, D. (2006). The body as interactive display: Examining bodies in a public exhibition. Sociology of Health \& Illness, 28, 223-251.

Vygotsky, L. S. (1978). Mind in society. Cambridge. MA: Harvard University Press.

Wankel, C. (1936). Fire kunstnere, gruppeportrett [Four artists]. Oil on canvas. The National Museum of Art, Architecture and Design, Oslo (NG.M.04295)

Wertsch, J. V. (1985). Vygotsky and the social formation of mind. Cambridge, MA: Harvard University Press.

Wertsch, J. V. (1998). Mind as action. New York, NY: Oxford University Press.

Wilson, M. (2002). Six views of embodied cognition. Psychonomic Bulletin \& Review, 9, 625-636.

Wölfflin, H. (1915). Kunstgeschichtliche Grundbegriffe [Principles of art history]. Munich, Germany: F. Bruckmann. 